\title{
INFLUÊNCIA DOS MEIOS DE CULTURA NA GERMINAÇÃO IN VITRO DE PASSIFLORA SUBEROSA L.
}

\author{
Quezia Pains Dutra ${ }^{1}$ \\ João Otavio da Silva Malaquias ${ }^{2}$ \\ Darley Aparecido Tavares Ferreira ${ }^{3}$ \\ Milene Miranda Praça Fontes ${ }^{4}$
}

\begin{abstract}
Resumo: O gênero Passiflora L. é o maior da família Passifloraceae, compreendendo cerca de 525 espécies. No Brasil, 141 espécies são registradas, das quais 85 são endêmicas. Dentre as espécies encontradas no Estado do Espírito Santo, destacamos a Passiflora suberosa, também conhecida como maracujazinho-cortiça-preto que é uma espécie tropical, utilizada como planta medicinal. Em busca de conhecimento científico e de conservação da espécie, a cultura in vitro vem sendo empregada para propagação e melhoramento genético. Portanto, o objetivo deste trabalho, foi identificar a influência de diferentes meios de cultura na germinação in vitro de $P$. suberosa, com a finalidade de desenvolver estratégias para adaptação da cultura in vitro, a fim de obter plântulas em condições assépticas e controladas. Sementes de P. suberosa foram desinfestadas e inoculadas nos meios MS, MS $1 / 2$, AAS e B5. As respostas obtidas in vitro foram a formação de calos e obtenção de plântulas inoculadas nos meios MS, MS1/2 e B5.
\end{abstract}

Palavras-chave: Passifloras; cultura in vitro; Calos.

\footnotetext{
1 Ciências Biológicas Licenciatura/Universidade Federal do Espírito Santo, Brasil. E-mail: quezia_dutra@hotmail.com.

2 Ciências Biológicas Licenciatura/Universidade Federal do Espírito Santo, Brasil. E-mail: joaootaviosm@gmail.com.

3 Doutorando em Genética e Melhoramento/Universidade Federal do Espírito Santo, Brasil. E-mail: darleytavarez@gmail.com.

${ }^{4}$ Professora Doutora/Universidade Federal do Espírito Santo, Brasil. E-mail: milenemiranda@yahoo.com.br.
} 